\title{
Ligações entre o ensino de ginástica artística escolar e o desenvolvimento motor de crianças: um estudo de revisão
}

\section{Links between the teaching of artistic gymnastics and school children's motor development: a review study}

\author{
${ }^{1}$ Thais Vinciprova Chiesse de Andrade thaisvinciprova@hotmail.com \\ ${ }^{1}$ Érica Cristina da Silva Rocha \\ ${ }^{1}$ Marcelo Paraíso Alves \\ ${ }^{1}$ Maria da Conceição Vinciprova Fonseca
}

\section{RESUMO}

Em virtude de novas tecnologias e mudanças características da contemporaneidade, a falta de atividade física e estímulos motores estão cada vez mais comuns. Isso torna o papel do professor de Educação Física ainda mais importante, visto que muitos alunos são quase exclusivamente estimulados a práticas orientadas de exercícios físicos durante a aula de Educação Física Escolar. O presente estudo tem como objetivo discutir a contribuição da Ginástica Artística (GA) para o desenvolvimento motor da criança no Ensino Fundamental - anos iniciais. A metodologia é composta de uma a revisão bibliográfica, onde buscaram-se artigos, livros, sites e anais de eventos relacionados ao tema, além de dissertações e teses que tratam da temática. O estudo é relevante na medida em que procura discutir a Ginástica Artística como colaboradora no processo de desenvolvimento motor da criança, oportunizando outro enfoque à modalidade, na maioria das vezes vista como um esporte de alto nível e difícil acesso, sendo quase inexistente na escola. Um segundo aspecto a ser ressaltado é a carência de estudos e publicações sobre a GA, o que dificulta o aprimoramento de profissionais interessados em atuar na modalidade. A Ginástica Artística possui características próprias que podem servir para aumentar os estímulos motores e desafiar o aluno a buscar mais, o que justifica sua presença entre os conteúdos do Ensino fundamental - anos iniciais. Fazendo uma análise das habilidades motoras que devem ser desenvolvidas nessa fase escolar, identificou-se uma relação direta das mesmas com as atividades desenvolvidas na Ginástica Artística.

Palavras-chave: Ginástica Artística, Desenvolvimento Motor, Ensino Fundamental.

\begin{abstract}
New technologies and changes that characterize the contemporary way of life are responsible for an increasing lack of physical activity, which makes the role of the physical education teacher even more important, since many students are almost exclusively stimulated only during Physical Education class. This study aims to discuss the contribution of Artistic Gymnastics (AG) for children's motor development in elementary education - early years. The methodology consists of a literature review of articles, books, websites and conference proceedings related to the topic, and dissertations and theses on the same theme. The study is relevant in that it discusses artistic gymnastics as a collaborator in the child's motor development process, providing opportunities to observe AG through different focuses, once it is often seen as a top-level sport and difficult to access, thus almost nonexistent in school. A second aspect to be highlighted is the lack of studies and publications on AG, which hinders the improvement of professionals interested in working with the sport. It can be seen that Artistic Gymnastics has its own characteristics that can help to increase motor stimuli and challenge students to seek more, thus being a good choice of content for elementary education - early years. An analysis of motor skills which should be developed in this school stage identifies a direct relationship between those and the activities developed in Artistic Gymnastics.
\end{abstract}

Key words: Artistic Gymnastics, Motor Development, Elementary School.

1 Centro Universitário de Volta Redonda, UniFOA. 


\section{INTRODUÇÃO}

A Educação Física no Ensino Fundamental é um componente curricular obrigatório de extrema importância no desenvolvimento motor, cognitivo, afetivo e social do aluno. A criança, ao longo do processo escolar, tende a ampliar suas habilidades motoras, aperfeiçoando seus movimentos (BRASIL, 1998).

No entanto, em virtude das novas tecnologias e mudanças que estão acompanhadas à contemporaneidade, é cada vez mais evidente a falta de atividade física e, consequentemente, de estímulos motores (AIROLDI, 1997).

Assim, o papel do professor de Educação Física torna-se fundamental para o bom desenvolvimento de seus alunos, uma vez que, hoje, muitas crianças só têm a oportunidade de serem estimuladas e vivenciarem experiências motoras nas aulas de Educação Física.

Os Parâmetros Curriculares Nacionais (PCN) reconhecem e enfatizam o papel basilar da Educação Física no Ensino Fundamental e orientam sobre a necessidade de possibilitar aos alunos desenvolverem, por meio dessas aulas, as suas habilidades corporais, e também de participarem de atividades culturais como jogos, lutas, esportes, ginásticas e danças, com a finalidade de formar o aluno como sujeito cidadão (BRASIL, 1998. Grifo acrescentado).

Dentre a multiplicidade de modalidades de ginástica, a Ginástica Artística (GA), além de trabalhar diversas habilidades motoras, oferece por meio da sua prática uma melhora nas valências físicas da criança (VIEIRA, 2013). Ela tem também uma ampla significância por contribuir no avanço motor, cognitivo, afetivo e social, no momento em que propicia atividades em grupo (COLETIVOS DE AUTORES, 2009).

Diferentes autores (SOUZA, 1997; NUNOMURA; NISTA-PICCOLO, 2005; SAWASATO; CASTRO, 2006; ANDRADE, 2010) afirmam que a GA é uma atividade corporal que contribui para o desenvolvimento das crianças, e que serve como base para a prática de outras atividades e esportes, além de trazer os benefícios como coordenação, confiança, disciplina, organização e criatividade.

Assim, este trabalho tem como objetivo discutir a contribuição da Ginástica Artística para o desenvolvimento motor da criança no Ensino Fundamental - anos iniciais. Acreditamos que seu (da GA) conteúdo tenha um diferencial que justifica essa empreitada: os movimentos específicos e os aparelhos peculiares usados para seu desenvolvimento. Por meio deles, o aluno é capaz de vivenciar movimentos pouco realizados no dia a dia. Tais movimentos serão explorados por meio do incentivo e mediação do professor de Educação Física.

A metodologia utilizada neste trabalho é a revisão bibliográfica. Buscamos artigos, livros, sites e anais de eventos relacionados ao tema, além de dissertações e teses que defendem a proposta. Segundo Marconi e Lakatos (2008), a pesquisa bibliográfica, ou fontes secundárias, engloba a bibliografia já existente no tema, e, ao agrupar aspectos pertinentes a um determinado foco, traduz-se em fonte para outros pesquisadores. Por isso deve ser tornada pública em obras especializadas, sejam revistas, livros, periódicos, além de divulgada em comunicações acadêmicas. A revisão bibliográfica possibilita, portanto, que o pesquisador tenha contato com aquilo que já foi escrito sobre a temática de seu interesse, conscientizando-o quanto ao estado de arte da questão.

Nessa perspectiva, a intenção neste trabalho é correlacionar o desenvolvimento motor, a GA e as crianças dos anos iniciais do Ensino Fundamental, na busca de uma educação holística, sempre apontando a Ginástica Artística como uma opção interessante e capital, de conteúdo, para as aulas de Educação Física Escolar.

Ao fazer a pesquisa na literatura, percebemos uma carência de estudos e pesquisas que abordem a Ginástica Artística. 
Segundo diversos autores, dos 146 artigos estudados e que abordam o ensino da Educação Física escolar, o esporte ocupa o lugar central nos conteúdos utilizados pelos docentes, conforme podemos visualizar: 42 tratam sobre Esportes (29\%), 32 sobre Jogos e Brincadeiras (22\%), 25 Dança (17\%), 16 Ginástica (11\%), 4 Capoeira (3\%), 3 Lutas (2\%) e 24 abordam Vários Conteúdos (16\%). Dos 11 artigos sobre Ginástica, apenas um faz referência à GA, conforme disposto a seguir: 2 artigos de Ginástica Geral, 1 de Ginástica Acrobática, 5 de Ginástica Circense, 2 sobre Ginástica Rítmica e 1 de Ginástica Artística. (NISTA-PICCOLO, NUNOMURA, 2005; ANDRADE, 2012; MATOS et al, 2013. Grifo acrescentado.)

Essa carência enfatiza a relevância deste trabalho, por aumentar a visibilidade da GA e suas possibilidades de aplicação. Na perspectiva da GA na escola não é diferente: dos 146 artigos estudados em sua pesquisa e que abordam o ensino da Educação Física escolar, o esporte ocupa o lugar central nos conteúdos utilizados pelos docentes: 42 artigos tratam de Esportes (29\%), 32 de Jogos e Brincadeiras (22\%), 25 de Dança (17\%), 16 de Ginástica (11\%), 4 de Capoeira (3\%), 3 de Lutas (2\%) e 24 abordam conteúdos variados (16\%). Dos 11 artigos sobre Ginástica, apenas um faz referência a GA, conforme disposto a seguir: 2 artigos de Ginástica Geral, 1 de Ginástica Acrobática, 5 de Ginástica Circense, 2 de Ginástica Rítmica e 1 de Ginástica Artística (MATOS et al., 2013. Grifo acrescentado).

\section{A GINÁSTICA ARTÍSTICA E SUAS POSSIBILIDADES}

A Ginástica Artística é uma modalidade pouca conhecida, se comparada a outros esportes. No entanto, devido aos excelentes resultados obtidos nas competições nacionais e internacionais por atletas como Arthur Zanetti, campeão olímpico nas argolas 2012; Flávia Saraiva; Daniele Hypólito; Diego Hypólito, pódios em mundiais, esta modalidade vem se popularizando cada vez mais (NUNOMURA; NISTA - PICCOLO, 2005).

Atualmente, a GA pode ser vista a partir de suas diferentes finalidades, ou seja, suas possibilidades de aplicações se diversificaram. As mais comuns são: Atividade Física e Esporte de Alto Rendimento (SAWASATO; CASTRO, 2006).

A Ginástica Artística referida como Esporte de Alto Rendimento é dividida em Ginástica Artística Masculina (GAM) e Ginástica Artística Feminina (GAF). Os aparelhos da GAM são diferentes da GAF. Enquanto os homens disputam em 6 aparelhos, as mulheres disputam em 4. Os aparelhos masculinos são: o solo, argola, salto sobre a mesa, cavalo com alças, barras fixas e barras paralelas. Já os femininos são: as barras assimétricas, trave, o solo, e o salto sobre a mesa (SAWASATO; CASTRO, 2006).

A GA competitiva (de alto rendimento) tem seu planejamento bem estruturado desde o seu trabalho de base, evoluindo com a preocupação voltada para a perfeição dos movimentos e ênfase na execução técnica, que fica mais complexa a cada ciclo olímpico, onde sofre alterações no Código Internacional de Pontuação da Federação Internacional de Ginástica (FIG) (SAWASATO; CASTRO, 2006).

Assim, os elementos da GA, dentro do código de pontuação, estão divididos por: A- fáceis; B- médio; Cdifíceis, além das dificuldades: D- alta dificuldade; E- altíssima dificuldade; e Super E- extrema complexidade (SAWASATO; CASTRO, 2006).

No esporte de alto rendimento, a performance na execução técnica e postural dos elementos desenvolve a coordenação de rotações simples e múltiplas em torno dos próprios eixos corporais. São finalizações controladas e estáveis (SAWASATO; CASTRO, 2006).

A GA com finalidade de atividade física por meio dos movimentos naturais e espontâneos, faz com que os alunos desenvolvam com a maior amplitude e dinamismo as suas ações motoras: saltos, giros no eixo longitudinal e transversal, deslocamento, equilíbrio, passagem pelo apoio e apoio e suspensão invertidos, balanço em 
apoio e suspensão. Esses movimentos, quando coordenados e enriquecidos progressivamente, se transformam em elementos acrobáticos (LEGUET, 1987).

Esse tipo de atividade física, pensado e estruturado como ferramenta educativa, faz com que as crianças percebam e tenham consciência das suas próprias possibilidades motoras e aptidões, percebendo o quanto são capazes (SAWASATO; CASTRO, 2006).

Visto que neste trabalho abordamos a Ginástica Artística na escola, a finalidade que melhor contempla tal foco é a da GA - atividade física, pois na Educação Física Escolar não devemos enfatizar a performance e os gestos técnicos, e sim utilizar o conteúdo como ferramenta para alcançar um objetivo maior, como, por exemplo, a melhora no desenvolvimento motor (SCHIAVON; NISTA-PICCOLO, 2006).

\title{
3 O DESENVOLVIMENTO MOTOR E A GINÁSTICA ARTÍSTICA
}

Segundo Pellegrini,

\begin{abstract}
O desenvolvimento motor consiste em uma série de mudanças que ocorrem ao longo do ciclo vital em termos do deslocamento de partes do corpo ou de todo o corpo no espaço. O movimento é o elemento central na comunicação e interação com as outras pessoas e com o meio ambiente à nossa volta; é central também na aquisição do conhecimento de si e da natureza. Apesar dos movimentos estarem presentes em todas as nossas ações, eles não se repetem, variando em função da nossa disposição física e mental daquele momento. A aquisição de habilidades motoras que ocorre ao longo dos anos é fruto não só das disposições do indivíduo para a ação, mas principalmente do contexto físico e sócio-cultural onde o individuo está inserido (PELLEGRINI et al, 2005 p.179).
\end{abstract}

Assim, o desenvolvimento motor não é algo natural que ocorre de forma igual para todos; ele sofre grande influência do meio, o que torna ainda mais importante a Educação Física Escolar, sendo o momento em que o professor deve estimular o máximo possível seus alunos a aumentarem seu repertório motor, suas vivências e experiências (GALLAHUE; OZMUN, 2005).

Segundo Airoldi (1997), muitas são as causas que contribuem negativamente para o desenvolvimento das crianças, inclusive o próprio meio em que ela vive: a falta de espaço físico moradia, os lazeres tecnológicos televisão, computadores, vídeo game ， as distâncias entre os clubes e áreas públicas de lazer ou até mesmo a violência urbana são obstáculos para que as crianças possam explorar seus próprios movimentos com maior liberdade.

Betti e Zuliani (2002) afirmam que a atividade corporal é fundamental na vida infantil nos anos iniciais do Ensino Fundamental. A estimulação psicomotora adequada e diversificada está diretamente relacionada com o desenvolvimento cognitivo, afetivo e social do aluno. Desta maneira, o professor, nas aulas de Educação Física dos anos iniciais, deve dar prioridade ao desenvolvimento das habilidades motoras básicas, jogos e brincadeiras e atividades de autotestagem. Nessa etapa do ensino, a busca deve ser pelo potencial psicomotor dos alunos, deixando a aprendizagem de uma habilidade técnica em segundo plano. Um ambiente e um estado de espírito lúdico e prazeroso devem ser reforçados.

Gallahue e Ozmun (2005) dividem o desenvolvimento motor em 4 fases: Fase motora reflexiva (do útero até 1 ano de idade); Fase motora rudimentar (de 1 a 2 anos); Fase motora fundamental (de 2 anos a 7 anos de idade); Fase motora especializada dos esportes (de 7 anos em diante).

Essas fases motoras estabelecidas pelos autores são divididas por faixa etária aproximada e estágios. Uma vez que este trabalho trata de crianças do Ensino Fundamental - anos iniciais ( $1^{\circ}$ ao $5^{\circ}$ ano / 6 a 10 anos), nos 
limitaremos a explicar apenas as fases e estágios correspondentes às mesmas (Fase motora fundamental - estágio maduro (6 a 7 anos) e fase motora especializada - estágio transitório (7 a 10 anos).

A escolha pelos anos iniciais do Ensino Fundamental se deu pelo fato de autores desenvolvimentistas afirmarem que determinados movimentos devem estar em seu estágio maduro nesta etapa da vida (GALLAHUE; OZMUN, 2005). Sendo assim, defendemos que não será proveitoso inserir a GA como conteúdo de ensino nos anos finais do Ensino Fundamental, pois nesse estágio os alunos já devem saber executar determinados movimentos.

Vejamos a seguir as fases e estágios para uma melhor compreensão.

A fase dos movimentos fundamentais é dividida em 3 estágios: inicial ( 2 a 3 anos), elementar ( 4 a 5 anos) e maduro (6 a 7 anos). Os movimentos são classificados como: manipulativos, locomotores e estabilizadores.

Segundo os autores que sustentam esta pesquisa, é na fase dos movimentos fundamentais que as crianças estão aptas a explorarem o potencial do movimento de seu corpo, por meio da exploração espacial (locomoção), do controle muscular quando em oposição da gravidade (estabilização), do contato de precisão com diversos objetos em seu meio (manipulação).

Esta fase do desenvolvimento motor (fundamental) representa um período no qual as crianças estão ativamente envolvidas na exploração e na experimentação das capacidades motoras de seus corpos. Os padrões de movimentos fundamentais são os padrões básicos de comportamento observáveis (correr, pular, saltar, aterrissar, entre outros).

Um dos principais erros conceituais em relação às fases dos movimentos fundamentais é a noção de que as habilidades são determinadas de acordo com a maturidade e são pouco influenciadas pela tarefa e por fatores ambientais. A maturação desempenha um papel básico no desenvolvimento de padrões de movimentos fundamentais, mas não deve ser considerada como a única influência. Já as condições do ambiente desempenham papel importante no grau máximo de desenvolvimento nos padrões de movimento fundamentais (GALLAHUE; OZMUN, 2005).

Os parágrafos anteriores retratam a Fase Motora Fundamental como um todo. Segundo Gallahue e Ozmun (2005), no estágio maduro - 6 e 7 anos- a criança está ativamente envolvida na experimentação e exploração de suas capacidades motoras. O estágio maduro é caracterizado por desempenhos mecanicamente eficientes, coordenados e controlados. É importante ressaltar que a grande maioria das crianças necessita de estímulos que oportunizem a prática, o encorajamento e a instrução em um ambiente que promova o aprendizado para atingirem esse estágio, raramente atingido sem muita influência do ambiente, apenas com a maturação.

Nessa perspectiva, Gallahue e Ozmun (2005) fazem um quadro com sequências de aparecimento de habilidades de estabilidade selecionada, onde afirmam que no estágio maduro a criança deve executar o rolamento para frente de forma refinada (padrão de movimento - equilíbrio dinâmico), suportar o peso corporal em posição invertida com três apoios (padrão de movimento - equilíbrio estático).

O mesmo processo é feito para as habilidades locomotoras selecionadas, onde as crianças devem estar com padrão de salto maduro, saltitar habilmente com alternância rítmica, galopar e executar o salto misto completo (GALLAHUE; OZMUN, 2005).

Ao relacionarmos as habilidades apontadas pelos autores desenvolvimentistas Gallahue e Ozmun (2005) e as ações gímnicas mencionadas por Leguet (1987), percebemos que existe uma ligação direta entre elas. Segundo Leguet, nos primeiros passos da modalidade a criança deve aterrissar, equilibrar-se, girar sobre si mesmo, 
balancear em apoio, balancear em suspensão, passar pelo apoio invertido, passar pela suspensão invertida, deslocar-se bipedicamente, executar passagem pelo solo, executar abertura e fechamento, executar volteio, saltar.

Assim, reforçamos a importância de trabalharmos a GA como conteúdo no Ensino Fundamental, pois ela possui uma variedade de movimentos, locomotores e estabilizadores, específicos do desporto, que são apontados por Gallahue e Ozmun (2005) como objetivos a serem alcançados ainda na infância.

Na fase motora especializada (estágio transitório - 7 aos 10 anos), as habilidades motoras são resultados da fase motora fundamental. O movimento torna-se uma ferramenta que se aplica a muitas atividades motoras complexas presentes na vida diária, na recreação e nos desportos. É neste período que outras habilidades estabilizadoras, manipulativas e locomotoras são progressivamente refinadas, combinadas e elaboradas para o uso em situação crescente (GALLAHUE; OZMUN, 2005).

Os autores mostram em forma de quadros como as habilidades motoras fundamentais são refinadas e utilizadas na fase especializada em alguns desportos: vôlei, basquete, atletismo, futebol e ginástica, entre outros. O quadro relacionado à Ginástica reforça a importância de trabalhar esse conteúdo dentro das aulas de Educação Física, visto que muitos movimentos apontados pelos autores não são movimentos naturais realizados no dia a dia e precisam de estímulos para serem executados (exemplo: parada de três apoios).

\section{EDUCAÇÃO FÍSICA, ENSINO FUNDAMENTAL E GINÁSTICA ARTÍSTICA}

Desde os primórdios da humanidade, o ser humano sente a necessidade de praticar atividades físicas, seja para o prazer ou até mesmo para sobreviver às dificuldades impostas pelas condições da vida cotidiana. Com o decorrer dos tempos, a Educação Física iniciou sua caminhada rumo à legitimação perante a sociedade. Prova disso ocorreu a partir de sua inserção nas atividades ministradas nas instituições escolares (BRASIL, 1998).

A Educação Física no Ensino Fundamental deve possibilitar que os alunos tenham a oportunidade de desenvolver as habilidades corporais, participando de atividades culturais como jogos, lutas, ginásticas, esportes e danças, contribuindo para a sua formação ao buscar desenvolver sua autonomia, cooperação, participação social, valores e princípios democráticos (BRASIL, 1998).

As crianças ingressam no Ensino Fundamental com 6 anos de idade, e este tem uma duração prevista de 9 anos de estudos. Assim, os anos iniciais do Ensino Fundamental encontram-se no período chamado terceira infância, que compreende dos 6 aos 11 anos. Esse período se refere ao desenvolvimento físico quando o crescimento diminui, a força e a habilidades atléticas aumentam, as doenças respiratórias são mais comuns e a saúde é melhor do em qualquer outro período do ciclo vital (PAPALIA; OLDS; FELDMAN, 2006).

Segundo os PCN da área (1998), o componente curricular obrigatório corrobora o reconhecimento das características do estágio citado acima, devendo ser oportunizado o desenvolvimento da autonomia, que possibilita ao aluno monitorar suas próprias atividades, regularizando seus esforços, traçando metas, reconhecendo suas potencialidades e limitações, diferenciando os trabalhos corporais e sabendo o que pode ser prejudicial à saúde.

No âmbito escolar, a Educação Física é a disciplina responsável por apresentar aos alunos o universo da cultural corporal. A estimulação psicomotora nas aulas de Educação Física proporciona aos alunos a exploração de seus corpos e do ambiente que os cerca, possibilitando que eles desenvolvam aspectos cognitivos, afetivos, psicomotores e sociais, fazendo-se imprescindível para o aprendizado e desenvolvimento global (BRASIL, 1998).

Assim, os PCN determinam quais são os objetivos gerais de Educação Física no Ensino Fundamental, dentre os quais cabe ressaltar que os alunos devem ser capazes de 
Solucionar problemas de ordem corporal em diferentes contextos, regulando e dosando o esforço em um nível compatível com as possibilidades, considerando que o aperfeiçoamento e o desenvolvimento das competências corporais decorrem de perseverança e regularidade e devem ocorrer de modo saudável e equilibrado. (PCN, 1998, p.33)

Segundo Leguet (1987), recomenda-se a prática da GA nas aulas de Educação Física no Ensino Fundamental visando despertar o interesse da criança para os seus próprios movimentos, o que ajudará no seu desenvolvimento psicológico e físico, motivando-a para outras modalidades. Além disso, quando ela tem contato com outras crianças na escola, cria-se a oportunidade de desenvolver o aspecto afetivo, cognitivo e motor, consequentemente facilitando e estimulando a prática da GA.

A Ginástica Artística pode ser vivida na escola, no clube ou nas associações esportivas, sempre em grupo. É sempre neste ambiente humano particular que a criança desenvolve a sua personalidade cognitiva, afetiva e motora. Algumas atividades que trabalham esses aspectos são experimentar dimensões, criar, recriar, descobrir atividades, procurar soluções, ajudar os seus colegas, tomar decisões, distribuir tarefas (LEGUET, 1987).

Ainda segundo o mesmo autor, a GA na escola pode desenvolver nos seus alunos capacidades físicas e psicológicas, como o fortalecimento dos membros superiores e membros inferiores, identificação dos segmentos corporais, exploração do peso e da força, desenvolvimento das ações motoras, controle de equilíbrio, cooperação e coordenação, entre outras.

Terminamos com Freire (1993), que considera a Educação Física de suma importância para a criança de 6 a 10 anos, uma vez que nesta fase elas desenvolvem uma boa coordenação, além dos aspectos sociais e cognitivos, indispensáveis para o seu crescimento mental e físico. Por tudo isso, defendemos a centralidade da GA para que a Educação Física atinja seus objetivos.

\section{CONSIDERAÇÕES FINAIS}

A Ginástica Artística é um potente objeto de aprendizagem no Ensino Fundamental, dada a vasta diversificação de seu repertório motor, que possui relação direta com os movimentos fundamentais a serem desenvolvidos pelos alunos do Ensino Fundamental - anos iniciais.

Na escola, a GA não deve ser vista como um esporte de alto rendimento, mas sim como uma atividade física de base, educativa e formativa, que faz parte da diversidade da cultura corporal inserida no currículo da Educação Física. É uma modalidade esportiva fundamental para o desenvolvimento das crianças, tendo seus gestos motores uma progressão pedagógica até os extremamente complexos, oportunizando a seus alunos uma experimentação diferenciada daquela a que estão habituados nas aulas de Educação Física, e permitindo uma possibilidade de ampliação do repertório motor.

Embora atualmente a lei permita que os professores generalistas ministrem as aulas de Educação Física sem a formação específica em um Curso Superior em Licenciatura, entendemos que esses professores não estão preparados para tal função, que requer um conhecimento abrangente sobre a Ginástica Artística.

Finalmente, a Ginástica Artística, por possuir características próprias, serve para aumentar os estímulos motores e desafiar o aluno a buscar sempre mais, constituindo-se em um conteúdo relevante para o Ensino Fundamental - anos iniciais, visto que nesse período a criança está na fase motora fundamental - estágio maduro, e na fase motora especializada - estágio transitório. Como mostramos ao longo do trabalho, fazendo uma análise das habilidades motoras que devem ser desenvolvidas nessa fase escolar, existe uma relação direta das mesmas com as atividades desenvolvidas na Ginástica Artística, o que reforça a pertinência da proposta de aumentar a prática da Ginástica Artística para esses alunos. 


\section{REFERÊNCIAS}

AIROLDI, G.P.S. A ginástica artística na escola: um encontro possível. Campinas 1997.

ANDRADE, T.V.C. Um outro olhar sobre a ginástica artística. Anais do II Seminário Internacional de Ginástica Artística e Rítmica de Competição Campinas - SP, 29 e 30 de junho de 2010.

BETTI, M.; ZULIANI, L. R. Educação física escolar: uma proposta de diretrizes pedagógicas. Revista Mackenzie da educação física e esporte, v. 01, n 012002 p. 73- 81.

BRASIL. Secretaria de Educação Fundamental. Parâmetros curriculares nacionais: Educação Física / Secretaria de Educação Fundamental. Brasília: MEC / SEF, 1998.

COLETIVO DE AUTORES. Metodologia do Ensino de Educação Física. São Paulo: Cortez, 2009.

FREIRE, J. B. Educação de Corpo Inteiro. Teoria e Prática Física. Série: Pensamento e ação no magistério. Fundamentos para o magistério. Editora Scipione Ltda. São Paulo. 1993.

GALLAHUE, D. L; OZMUN, J. C. Compreendendo o desenvolvimento motor: Bebês, Crianças, Adolescentes e Adultos. 3.ed. São Paulo: Phorte, 2005.

LEGUET, Jacques. As Ações Motoras em Ginástica Esportiva, editora Manole Ltda. São Paulo. 1987.

MARCONI, M. A.; LAKATOS, E. M., Metodologia do trabalho científico: Procedimentos básicos, pesquisa bibliográfica, projeto e relatórios, publicações e trabalhos científicos, 7ed. 2 reimp. - São Paulo: Atlas, 2008.

MATOS, J. M.C.; SCHNEIDER, O.; MELLO, A. S.; NETO, A. F. N.; SANTOS, W. A produção acadêmica sobre conteúdos de ensino na educação física escolar. Revista Movimento, Porto Alegre, v. 19, n. 02, p. 123148, abr/jun de 2013.

NUNOMURA, M; NISTA-PICCOLO, V.L. Compreendendo a ginástica artística. São Paulo: Phorte, 2005.

PAPALIA, D.E. OLDS, S.W. FELDMAN, R.D. Desenvolvimento humano. 8 ed. Porto Alegre: Artmed, 2006.

PELlEGRINI, A. M., NETO, S., BUENO, F. C. R., ALLEONI, B. N., \& MOTTA, A. I. Desenvolvendo a coordenação motora no ensino fundamental. São Paulo: UNESP - 2005.

SAWASATO, Y.Y; CASTRO, M.F.C. A dinâmica da ginástica olímpica. (orgs.) GAIO, R.; BATISTA, J.C.F. In: A ginástica em questão. Ribeirão Preto, SP: Tecmed, 2006.

SCHIAVON, L.M, NISTA-PICCOLO, V.L. Desafios da ginástica na escola. In: Educação Física Escolar: propostas e desafios II / (Org.) MOREIRA, E.C. - Jundiaí, SP: Fontoura Editora, 2006.

SOUZA, E. P. M. Ginástica Geral: uma área do conhecimento da Educação Física. Tese de Doutorado, UNICAMP, Faculdade de Educação Física, Campinas (São Paulo), 1997.

VIEIRA, M, B. A importância da ginástica enquanto conteúdo da Educação Física escolar, Buenos Aires Año 18, No 180, Mayo de 2013. 